\title{
Intraocular Pressure Reactivity to Social Stressors
}

\author{
The Role of Self-Efficacy, Perceived Threat, \\ and Aversiveness of Non-Contact Tonometry
}

\author{
Antoni Sanz ${ }^{1}$ and Jorge Luis Méndez-Ulrich² \\ ${ }^{1}$ Research Group on Stress and Health, Department of Basic, Developmental and Educational Psychology, \\ Faculty of Psychology, Universitat Autònoma de Barcelona, Cerdanyola del Vallès, Spain \\ ${ }^{2}$ Department of Methods of Research and Diagnosis in Education, Faculty of Education, University of Barcelona, Barcelona, Spain
}

\begin{abstract}
A field study was carried out in an optometry clinic, aimed at assessing the role of perceived control and aversiveness of noncontact tonometry in intraocular pressure (IOP) reactivity to psychosocial stressors, and analyzing the covariation with cardiovascular and affective reactivity. Forty-four customers volunteered to participate in the study. Perceived control (self-efficacy and threat) was assessed at the onset. IOP, systolic and diastolic blood pressure, heart rate, affect, and aversiveness of the IOP measurement procedure were assessed throughout five phases with a mean duration for each phase of 9 min: arrival, optometry, baseline, stressor task (speech in public task), and recovery. The results suggest that IOP decreases over time and the stressor task induced a remarkable reactivity in all the physiological variables assessed. The interaction between self-efficacy and threat partially explains individual variability in IOP: a high threat combined with a high self-efficacy yielded higher reactivity in IOP or increased tonic values throughout the phases. The aversiveness of the measurement procedure did not affect IOP. Intraocular Pressure (IOP) is reactive to social stressors and perceived control partially explains individual variability. Cardiovascular and IOP reactivity are parallel phenomena but do not share a common regulatory mechanism.
\end{abstract}

Keywords: perceived control, self-efficacy, threat, intraocular pressure, cardiovascular reactivity, affect

Glaucoma is one of the main causes of blindness worldwide (Wilson et al., 2002). This condition causes progressive damage to the optic nerve (Bradford, 2004) through an increase in intraocular pressure (IOP) above the normal range, between $12 \mathrm{mmHg}$ and $20 \mathrm{mmHg}$ (Guyton \& Hall, 2006). However, this disease can also affect IOPnormotensive individuals (Rao, 2012). Although the damage to the optic nerve occurs from the onset of this disease, patients with glaucoma do not usually perceive any symptoms of their pathology until the damage to the optic nerve is already irreparable and there is a loss of the visual field and visual acuity (Blázquez, Sebastián, \& Antón, 2008). Early detection and prevention are therefore essential, since there is currently no effective cure for glaucoma, and treatment primarily focuses on maintaining stable levels of IOP (Fogagnolo \& Rossetti, 2011; Van der Valk et al., 2005). The level of IOP depends on the balance between the production and drainage of aqueous humor, a fluid that nourishes the anterior segment of the eye, which is evacuated through a structure called Schlemm's canal (Bradford, 2004; Kanski \& Bowling, 2011).
Despite the lack of studies on the psychophysiology of IOP, some authors (Brody, Erb, Veit, \& Rau, 1999; Erb, Brody, \& Rau, 1998; Kaluza \& Maurer, 1997; Kaluza, Strempel, \& Maurer, 1996; Sauerborn, Schmitz, Franzen, \& Florin, 1992) have provided evidence for the reactivity of IOP to various types of stressors ranging from $1.3 \mathrm{mmHg}$ to $1.7 \mathrm{mmHg}$. One hypothetical physiological basis of this reactivity lies in the sympathetic and parasympathetic regulation of the production and drainage of aqueous humor, which determines IOP (Chiquet \& Denis, 2004; Gherezghiher, Hey, \& Koss, 1990; Kanski \& Bowling, 2011). This is a regulatory mechanism that IOP shares with other dynamic processes of the eye such as pupil dilation (Chen et al., 2019). Chronic psychosocial stress has also been linked to higher levels of IOP (Yamamoto et al., 2008). Although the way in which IOP responsivity to stress can impact the course of glaucoma still remains unclear, the study by Méndez-Ulrich, Casas, and Sanz (2013) suggested that the sensitivity of IOP to stress could compromise the validity of its measurement through a hypothetical phenomenon analogous to white coat hypertension 
(MacDonald, Laing, Wilson, \& Wilson, 1999; Ogedegbe et al., 2008; Pickering, Gerin, \& Schwartz, 2002), which is referred to as ocular white coat hypertension (OWCH). As in the case of white coat hypertension (MacDonald et al., 1999; O’Brien et al., 2003), OWCH could be mediated by the degree of perceived control and threat related to the clinical context and the invasive and aversive properties of the measurement procedure. And similar to what has been found when measuring blood pressure (Enström, Pennert, \& Lindholm, 2000), there may be an increased physiological arousal induced by certain contextual variables involved in the IOP assessment procedure in clinical contexts that could be judged as stressful by the patient (due to, for instance, the invasion of personal space, uncertainty regarding health status, or the presence of the clinician). This could induce artificially high IOP levels, which could lead to an overdiagnosis (due to false positives) of glaucoma. Moreover, some interactions have been found between ocular pressure and cardiovascular function, such as the oculocardiac reflex, which appears to be regulated by both sympathetic and parasympathetic pathways (Paton, Boscan, Pickering, \& Nalivaiko, 2005).

Lazarus and Folkman (1984) highlighted the influence of cognitive assessment on stress levels and physiological reactivity. These authors identified a series of personal and situational factors (novelty, ambiguity, uncertainty or predictability of occurrence) that could be responsible for eliciting the stress response. These authors particularly emphasized the role of global control beliefs such as locus of control (Rotter, 1975) in the moderation of stress in ambiguous situations. In contrast, in the situations where such ambiguity does not exist, situational-specific beliefs such as self-efficacy and outcome expectancies (Bandura, 1977; Bandura, Reese, \& Adams, 1982) become the major factors influencing the stress response. Indeed, some studies have found a relationship between self-efficacy and physiological reactivity (Bandura, 1992; Bandura et al., 1982; Feltz \& Mugno, 1983; Gerin, Litt, Deich, \& Pickering, 1995; Gerin, Litt, Deich, \& Pickering, 1996; Sanz \& Villamarín, 1997, 2001; Sanz, Villamarín, \& Álvarez, 2006; Sanz, Villamarín, Álvarez, \& Limonero, 2006; Sanz, Villamarín, Álvarez, \& Torrubia, 2007; Wright \& Dill, 1993; Wright \& Dismukes, 1995; Wright, Shaw, \& Jones, 1990). Moreover, the results of these studies suggest that selfefficacy usually interacts with situational or dispositional factors to regulate physiological reactivity, thus providing strong support for interactionist models of the personalityemotion-physiology relationship (Stemmler \& Wacker, 2010). In this regard, Sanz, Villamarín, and Álvarez (2006) assert that self-efficacy regulates cardiovascular reactivity primarily when the incentive value of the task is high (i.e., when the consequences of the behavior are perceived as important). The results of the latter study indicate that the highest cardiovascular reactivity occurs when the person is tested under conditions of low self-efficacy and high incentive value. Similarly, Gerin et al. (1995) have argued that coping with a painful stimulus through avoidance behavior can have an impact on cardiovascular reactivity. Therefore, competence and contingency beliefs (Skinner, 1996) could explain the individual variability in physiological reactivity when coping with stressful events or contexts (Sanz, Villamarín, Álvarez, \& Limonero, 2006).

Although the personality, cognitive, and affective mechanisms underlying cardiovascular reactivity related to stressful conditions have been extensively studied for decades, relatively little is known about how these processes affect intraocular pressure.

On the basis of the results obtained from previous research, the following hypotheses were formulated:

Hypothesis 1 (H1): Psychosocial stressors will induce significant IOP and cardiovascular reactivity.

Hypothesis 2 (H2): Individual differences in IOP reactivity to a psychosocial stressor will partially depend on the interaction between self-efficacy and threat.

Hypothesis 3 (H3): Aversiveness of the IOP measurement procedures will partially predict individual differences in IOP.

Hypothesis 4 (H4): When faced with a psychosocial stressor, there will be a strong correlation between IOP and cardiovascular reactivity.

One possible account of IOP reactivity that has been proposed in the scarce literature on this issue (Méndez-Ulrich et al., 2013) is the aversive properties of its measurement procedure, which have been related to (1) the invasion of personal space and (2) the manipulation of the eye. Therefore, in the present study a measure of this aversiveness was included in the IOP measurement procedure in order to test this hypothesis. A further factor that has been proposed to play a role in IOP reactivity is the impact of the clinical setting and the presence of the clinician. For this reason, the present study was conducted in a real-life clinical context (an optometry office) in which the participants received a clinical assessment of their ocular health status, thus providing our results with ecological validity (Brewer, 2000).

\section{Methods}

\section{Participants}

This study was carried out using a sample of participants who were required to undergo an optometric procedure at 
an optician located on the campus of the Autonomous University of Barcelona (UAB). A total of 44 customers voluntarily agreed to participate in the study, which was presented as a part of a campaign for the analysis and prevention of glaucoma. The exclusion criteria were: (1) Medical history of glaucoma or ocular hypertension; (2) previous eye surgery of any kind, and (3) consumption of any drugs (cannabis, etc.) that could affect IOP up to $2 \mathrm{hr}$ prior to the study. One participant was excluded due to having undergone glaucoma surgery in the past, and thus the final sample consisted of 43 participants, of which 28 were women $(68.3 \%)$. The mean age was 38 years $(S D=15.92$; range: $19-65)$, and $83.3 \%$ of the participants were right-handed. For the overall sample, the mean IOP upon arrival at the clinic was $14.19 \mathrm{mmHg}(S D=2.76$, range: 9-22) for the left eye (LE) and $13.62 \mathrm{mmHg}(S D=2.23$, range: $9-19)$ for the right eye (RE). Neither gender, $F(1,38)=0.80$; $n s$ for LE; $F(1,38)=1.76$; $n s$ for RE, or age $(r=.20$; $n s$ for LE; $r=$ .08 ; $n s$ for RE) predicted IOP upon arrival. In addition, men and women did not differ in terms of age, $F(1,38)=$ $0.16 ; n s$.

\section{Apparatus}

IOP was measured with a Keeler Pulsair Intelipuff ${ }^{\circledR}$ noncontact tonometer. Several studies have confirmed the comparability of this instrument with the Goldmann method (Parker, Herrtage, \& Sarkies, 2001; Lawson-Kopp et al., 2002). Goldmann applanation tonometry is the gold standard for IOP measurement. In this technique, direct, progressive pressure is applied to the previously anesthetized cornea. Noncontact tonometry is also a proven alternative method for IOP measurement (Ogbuehi \& Almubrad, 2008). Using this less invasive alternative, a soft air puff is applied to the cornea, which determines the level of IOP depending on the time between the puff and the resulting deformation on the cornea (Paul, 2006). According to the manufacturer, the error margin of this device is $\pm 1 \mathrm{mmHg}$.

Systolic blood pressure (SBP), diastolic blood pressure (DBP), and heart rate (HR) were measured with an oscillometric sphygmomanometer (Welch Allyn ${ }^{\circledR}$, Skaneateles Falls, New York, NY), following the recommendations of the Association for the Advancement of Medical Instrumentation for blood pressure automatic measurement (ANSI/AAMI, 2013). According to the manufacturer, the error margin is $\pm 3 \mathrm{mmHg}$.

\section{Psychometric Instruments}

A computerized form was created with Google Forms in order to record sociodemographic, exclusion and confounding variables (subjects, handedness, room temperature, hour, and date), and psychometric and physiological variables. We evaluated self-efficacy and perceived threat regarding the optometry procedure using the respective subscales of an ad hoc adaptation of the Spanish version of the Primary Appraisal and Secondary Appraisal scale (PASA; Gaab, Rohlederb, Natera, \& Ehlerta, 2005). These subscales have good internal consistency (Cronbach's $\alpha=.83$ and $\alpha=$ .81 for the threat and self-efficacy subscales, respectively). In order to assess affective valence, arousal, and dominance regarding the IOP measurement procedure, the Self-Assessment Manikin (SAM; Bradley \& Lang, 1994) was employed. SAM is a cross-cultural, pictographic instrument in which the affective dimensions are assessed on a scale ranging from 1 to 9 . The battery also included an ad hoc 1-10 point scale to assess the aversiveness of the IOP measurement procedure. The participants were asked to respond to the question "to what extent do you feel that the measurement of IOP was unpleasant for you?”.

\section{Procedure}

The procedure (Table 1) was designed as an extension of the optometric procedure that had been prescribed by an optician. Each participant was met by the optician (1 out of 3), who gave him/her the informed consent form to read and sign. In order to simulate the feeling of receiving a clinical evaluation, both the professionals and researchers of the center always wore a white coat during the session. The participant was then led to the optometry room and seated in the optometry chair. Each participant also received a brief explanation about the IOP measurement procedure. The sessions lasted $65 \mathrm{~min}$ on average, and when required, the participants interacted with the questionnaires through a monitor connected to a laptop placed in front of them. The session consisted of 5 phases, each lasting for approximately 9 min: arrival (Phase 1), optometry (Phase 2), baseline (Phase 3), social stressor task (Phase 4), and recovery (Phase 5). At the beginning of Phase 1 (arrival) the participants completed the PASA subscales of self-efficacy and threat. During Phase 2 (optometry) an optometric procedure was carried out by one of three optometrists (the same clinician that met and recruited the participant). All of them were staff members of the optometry center and were instructed so as to standardize their interaction with the participants in this phase. In Phase 3 (baseline), participants were left to rest alone while completing the online questionnaire to gather data related to sociodemographic, exclusion, and confounding variables. In the social stressor task (Phase 4), a shortened version of the public speaking task of the Trier Social Stress Test (TSST; Kirschbaum, Pirke, \& Hellhammer, 1993) was administered. In this task, the participants were asked to speak for $5 \mathrm{~min}$ about their main 
Table 1. Instruments employed and variables measured along the study

\begin{tabular}{|c|c|c|c|c|c|c|c|}
\hline \multirow[b]{2}{*}{ Category } & \multirow[b]{2}{*}{ Variable } & \multirow[b]{2}{*}{ Instrument } & \multicolumn{5}{|c|}{ Phase } \\
\hline & & & Arrival & Optometry & Baseline & Stressor & Recovery \\
\hline \multirow[t]{2}{*}{ Cognitive variables } & Self-efficacy & PASA & $\sqrt{ }$ & & & & \\
\hline & Threat & & $\sqrt{ }$ & & & & \\
\hline \multirow[t]{4}{*}{ Physiological variables } & IOP & Non-contact tonometer & $\sqrt{ }$ & $\sqrt{ }$ & $\sqrt{ }$ & $\sqrt{ }$ & $\sqrt{ }$ \\
\hline & SBP & Electro-Sphygmomanometer & $\sqrt{ }$ & $\sqrt{ }$ & $\sqrt{ }$ & $\sqrt{ }$ & $\sqrt{ }$ \\
\hline & DBP & & $\sqrt{ }$ & $\sqrt{ }$ & $\sqrt{ }$ & $\sqrt{ }$ & $\sqrt{ }$ \\
\hline & $\mathrm{HR}$ & & $\sqrt{ }$ & $\sqrt{ }$ & $\sqrt{ }$ & $\sqrt{ }$ & $\sqrt{ }$ \\
\hline \multirow[t]{4}{*}{ Affective variables } & Arousal & SAM & $\sqrt{ }$ & $\sqrt{ }$ & $\sqrt{ }$ & $\sqrt{ }$ & $\sqrt{ }$ \\
\hline & Valence & & $\sqrt{ }$ & $\sqrt{ }$ & $\sqrt{ }$ & $\sqrt{ }$ & $\sqrt{ }$ \\
\hline & Dominance & & $\sqrt{ }$ & $\sqrt{ }$ & $\sqrt{ }$ & $\sqrt{ }$ & $\sqrt{ }$ \\
\hline & Aversiveness & One-item scale & $\sqrt{ }$ & $\sqrt{ }$ & $\sqrt{ }$ & $\sqrt{ }$ & $\sqrt{ }$ \\
\hline
\end{tabular}

Note. PASA = Primary Appraisal-Secondary Appraisal Scale; IOP = Intraocular Pressure; SBP = Systolic Blood Pressure; DBP = Diastolic Blood Pressure; HR $=$ Heart Rate; $P C=$ Perceived Control; SAM = Self-Assessment Manikin .

virtues and defects in front of a video camera, in the presence of two persons: The main researcher (who conducted the physiological recordings) and a second experimenter who was falsely introduced as an expert in communication and whose hypothetical function was to assess the credibility of their speech. The participants were given $5 \mathrm{~min}$ to prepare the task, during which they remained alone in the experimental room with a sheet of paper and a pen for notemaking purposes, although the use of these notes was not permitted during the speech. The purpose of this 5-minute phase was to allow the participants to develop an anticipatory anxiety response. The cardiovascular variables were recorded during the $50 \mathrm{~s}$ leading up to the start of the task, and $2 \mathrm{~min}$ after the start of the task the participants were interrupted to record the IOP, informing them that they were in the middle of their task in order to maintain the activation induced by the stressor during the measurement of the IOP. Once these measurements had been recorded, the participant was informed that the task had ended. Finally, during recovery (Phase 5) the participant rested alone in the optometry room.

At the end of each of the five phases, SBP, DBP, and HR were assessed, after which IOP was measured (twice per eye) following the pattern LE-RE-LE-RE. The maximum delay between the first and the fourth measurements was 2 min. Finally, arousal, valence, dominance, and aversiveness of the IOP measurement were assessed.

\section{Data Preparation}

The Statistical Package for Social Sciences v.22 for Windows was used for descriptive and inferential analyses. Independent variables (self-efficacy and threat) were dichotomized (high vs. low), by a median split. Further, 10 within-subject analyses of variance (ANOVAs) were conducted to compare the pairs of IOP measures obtained for each eye and phase. The results did not reveal any significant differences between the two IOP measures for either eye or phase, except for the LE in Phase 1, $F(1,41)$ $=4.51, p=.04$. Therefore, the two measures per eye per phase were averaged, and these values were employed in the next set of statistical analyses. For the rest of the dependent variables (SBD, DBP, HR, IOP, arousal, valence, dominance and aversiveness) raw data were used in the subsequent inferential analyses. In addition to the excluded participant, two other participants were considered as missing cases due to the fact that were unable to access their IOP records. Therefore, a total sample of 41 cases were used for the statistical analyses.

In order to test for the effect of threat and self-efficacy on physiological and affective variables, we conducted a set of analyses of variance (mixed model). For each dependent variable a Phase $(5) \times$ Threat (2) $\times$ Self-Efficacy (2) factorial model was planned, with phase being a within-subject factor, and threat and self-efficacy the between-subject factors.

\section{Results}

\section{Perceived Control, Physiological Reactivity, and Affective Response}

The ANOVA conducted on the SBP data revealed a main effect of phase (Wilks's $\Lambda=.22 ; F(4,24)=21.76$; $\left.p<.0005 ; \eta_{\mathrm{p}}^{2}=.78\right)$. A nonlinear, cubic model provided the best fit for the trend observed throughout the phases (Figure $\left.1 ; \mathrm{F}(1,27)=93.87 ; p<.0005 ; \eta_{\mathrm{p}}^{2}=.78\right)$. Bonferroni contrasts revealed the following order: phase ${ }_{1}>$ phase $_{2}=$ phase $_{3}<$ phase $_{4}>$ phase $_{5}$. The interaction Phase $\times$ Threat 


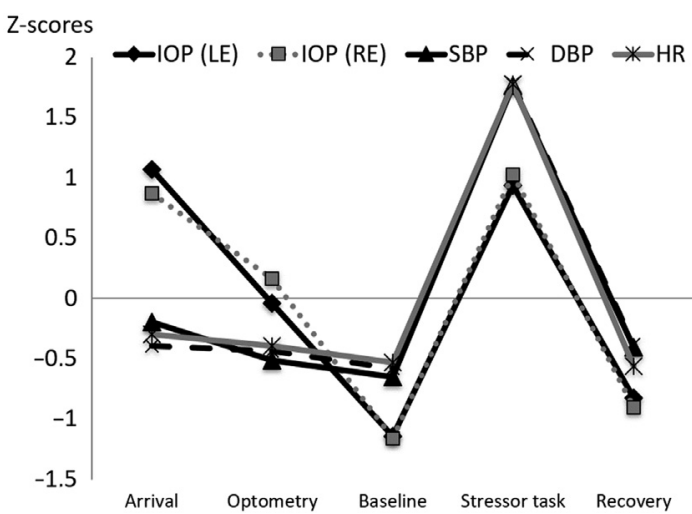

Figure 1. Patterns throughout the phases of the study for systolic blood pressure (SBP), diastolic blood pressure (DBP), heart rate (HR), and intraocular pressure (IOP) for left eye (LE) and right eye (RE). Values are in normalized units (Z-scores).

was also significant and fitted a cubic model, $F(1,27)=6.31$; $p=.01 ; \eta_{\mathrm{p}}^{2}=.19$. Analysis of simple effects revealed a significant difference between the groups for threat in phase ${ }_{4}$, $F(1,29)=7.72 ; p=.009 ; \eta_{\mathrm{p}}^{2}=.21$, and in phase $\mathrm{F}_{5}, F(1,29)=$ 3.98; $p=.04 ; \eta_{\mathrm{p}}^{2}=.12$. A between-subject ANOVA (Figure 2) revealed a main effect of threat, and the interaction between threat and self-efficacy approached significance. Simple effects analyses revealed higher SBP values for participants in the high threat group ( $M=132.40$ vs. $\left.M=114.87 ; F(1,15)=7.14 ; p=.01 ; \eta_{p}^{2}=.32\right)$ but only when self-efficacy was high.

The ANOVA conducted on the DBP data revealed a main effect of phase (Wilks's $\Lambda=.18 ; F(4,24)=27.06 ; p<.0005$; $\eta_{\mathrm{p}}^{2}=.82$ ). A nonlinear, cubic model provided the best fit for the trend observed throughout the phases (Figure 1; $\left.F(1,27)=95.34 ; p<.0005 ; \eta_{\mathrm{p}}^{2}=.78\right)$. Bonferroni contrasts revealed the following order: phase $_{1}=$ phase $_{2}=$ phase $_{3}<$ phase $_{4}>$ phase $_{5}$. Between-subject ANOVA (Figure 3) revealed main effects of threat and self-efficacy, and the interaction between these two variables approached statistical significance. Simple effects analyses revealed higher SBP values for participants in the high threat group $(M=$ 84.00 vs. $\left.M=73.78 ; F(1,15)=7.95 ; p=.01 ; \eta_{p}^{2}=.35\right)$ but only when self-efficacy was high.

The ANOVA conducted on the HR data revealed a main effect of phase (Wilks's $\Lambda=.26 ; F(4,24)=17.13 ; p<.0005$; $\left.\eta_{\mathrm{p}}^{2}=.74\right)$. A nonlinear, cubic model provided the best fit for the trend observed throughout the phases (Figure 1; $\left.F(1,27)=42.41 ; p<.0005 ; \eta_{p}^{2}=.61\right)$. Bonferroni contrasts revealed the following order: phase ${ }_{1}=$ phase $_{2}=$ phase $_{3}<$ phase $_{4}>$ phase $_{5}$. A significant interaction Phase $\times$ Threat $\times$ Self-Efficacy also appeared (Figure 4 ), which best fitted a cubic model, $F(1,27)=5.41 ; p=.02 ; \eta_{\mathrm{p}}^{2}=.17$. Simple effects analyses revealed higher levels of $\mathrm{HR}$ in phase $_{4}$ in

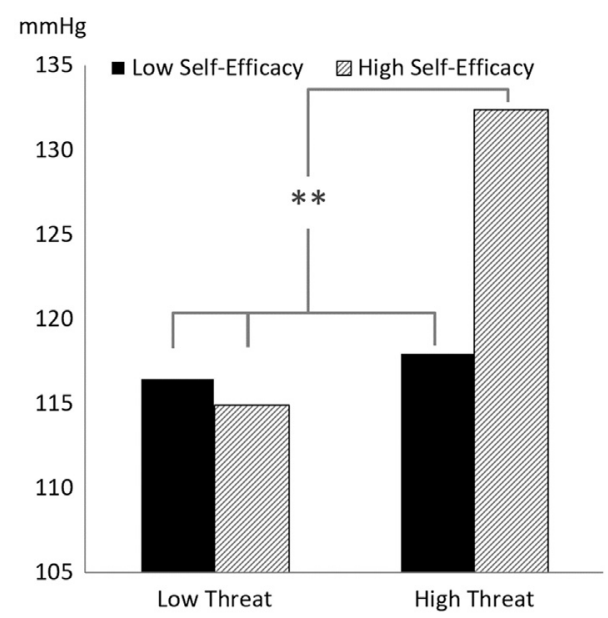

Figure 2. Estimated mean systolic blood pressure (SBP) as a function of dichotomized threat and self-efficacy (SE) scales for all phases of the study $(* * p<.01)$.

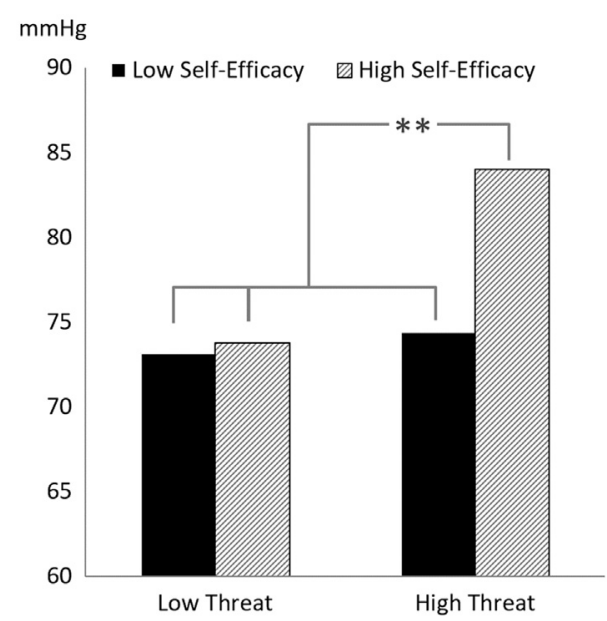

Figure 3. Estimated mean diastolic blood pressure (DBP) as a function of dichotomized threat and self-efficacy (SE) scales for all the phases $(* \star p<.01)$

the high threat group, but only when self-efficacy was low $\left(M=92.6\right.$ vs. $M=80.11 ; F(1,29)=7.72 ; p=.009 ; \eta_{p}^{2}=$ .21). The between-subject ANOVA did not reveal any significant effects.

A double ANOVA was carried out to analyze the IOP data. First, a Phase (5) $\times$ Eye (2) within-subject ANOVA was conducted on these data (Figure 5), revealing a main effect of eye (Wilks's $\Lambda=.83 ; F(1,37)=7.44 ; p=.01 ; \eta^{2}$ $=.17)$, with IOP values on LE $(M=13.78)$ being higher than those on $\mathrm{RE}(M=13.39)$. A main effect of phase was also found (Wilks's $\Lambda=.64 ; F(4,34)=4.79 ; p=.004 ; \eta_{\mathrm{p}}^{2}=$ .36), but the interaction Phase $\times$ Eye did not reach statistical significance. Contrast analyses for the phases revealed a trend that best fitted an order 4 model, $F(1,37)=20.55$; $p=.004$. Bonferroni contrasts revealed the following order: 


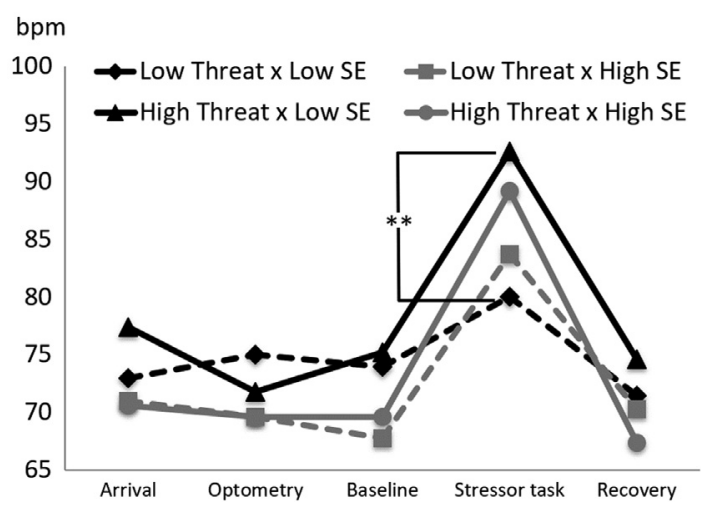

Figure 4. Estimated mean heart rate (HR) as a function of dichotomized threat and self-efficacy (SE) scales for each phase $(* * p<.01)$.

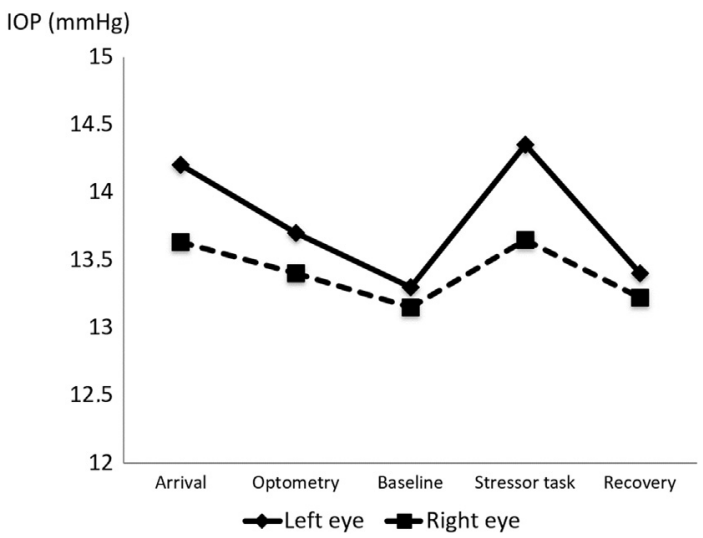

Figure 5. IOP (intraocular pressure) means for the LE (left eye) and RE (right eye) throughout the phases of the study.

phase $_{1}=$ phase $_{2}>$ phase $_{3}<$ phase $_{4}>$ phase $_{5}$. Therefore, the results suggest (Figure 2) a tendency for IOP to decrease in both eyes during the phases prior to introduction of the stressor, which peaks during the task, and then returns to baseline during the recovery phase. With regard to the specific changes in IOP during the stressor task in the whole sample ( $\Delta$ difference between stressor task and baseline), an increase was found in both eyes $(+.80 \mathrm{mmHg}$ for the $\mathrm{LE}$ and $+.42 \mathrm{mmHg}$ for the $\mathrm{RE}$ ) that reached statistical significance (Wilks's $\Lambda=.77 ; F(1,37)=11.62 ; p=.002$; $\eta_{\mathrm{p}}^{2}=.23$.

In order to conduct the subsequent ANOVA (within- and between-subject), we averaged the IOP across the LE and RE. We then conducted a Phase $(5) \times$ Threat $(2) \times$ SelfEfficacy ANOVA. This analysis revealed that the data followed the same pattern throughout the phases as that confirmed in the first step (Figure 1), and also showed a significant Phase $\times$ Threat interaction (Wilks's $\Lambda=.69$; $\left.F(4,26)=2.96 ; p=.03 ; \eta_{p}^{2}=.31\right)$. This analysis also confirmed the interaction Phase $\times$ Self-Efficacy long with a

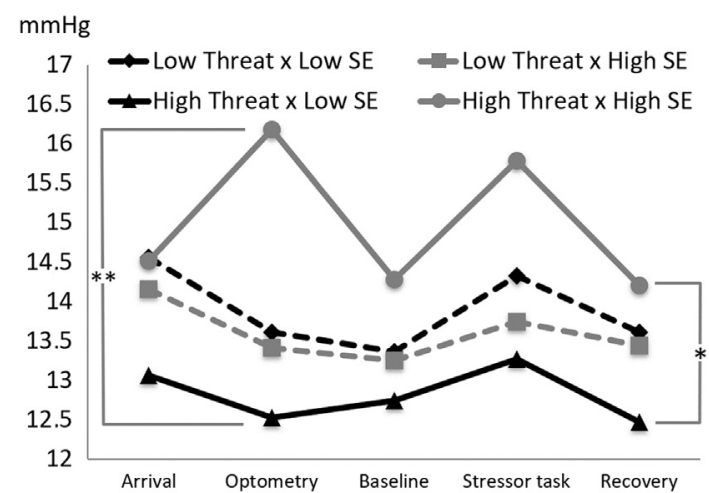

Figure 6. Estimated mean IOP (intraocular pressure) as a function of dichotomized threat and self-efficacy (SE) scales for each phase $\left({ }^{*} p<.05 ;{ }^{* *} p<.01\right)$.

near significant second order interaction Phase $\times$ Threat $\times$ Self-Efficacy. Therefore, a between-subject analysis (Figure 6) was then conducted for each phase. This analysis revealed that when the level of perceived threat was high, there was a significant effect of self-efficacy on IOP in phase $_{2}$ and phase ${ }_{4}$. Specifically, IOP was higher for the high self-efficacy condition in both phase ${ }_{2}(M=16.18$ in high vs. $M=12.53$ in low; $\left.F(1,10)=9.23 ; p=.01 ; \eta_{\mathrm{p}}^{2}=.48\right)$ as well as in phase ${ }_{4}(M=15.78$ in high vs. $M=13.27$ in low; $F(1,10)=$ $\left.4.66 ; p=.05 ; \eta_{\mathrm{p}}^{2}=.31\right)$. A similar trend was observed in phase $_{1}$, phase $e_{3}$, and phase ${ }_{5}$, but the differences did not reach statistical significance.

An ANOVA conducted on the arousal data revealed a main effect of phase (Wilks's $\Lambda=.16 ; F(4,28)=38.39$; $\left.p<.0005 ; \eta_{\mathrm{p}}^{2}=.85\right)$ which best fitted a nonlinear, cubic model (Figure 3; $F(1,31)=149.99 ; p<.0005 ; \eta_{p}^{2}=.83$ ). Bonferroni contrasts revealed the following order: phase ${ }_{1}$ $>$ phase $_{2}=$ phase $_{3}<$ phase $_{4}>$ phase $_{5}$. Further, a Phase $\times$ Self-Efficacy interaction fitted a cubic trend and reached statistical significance (Figure 7; $F(1,33)=3.91 ; p<.05$; $\eta_{\mathrm{p}}^{2}=.11$ ). Analysis of each phase (Figure 8) revealed a main effect of self-efficacy that reached statistical significance in phase $_{4}$ : higher self-efficacy induce lower arousal $(M=6.88$ vs. $\left.M=5.39 ; F(1,33)=6.07 ; p=.01 ; \eta_{\mathrm{p}}^{2}=.16\right)$.

The ANOVA conducted on the valence data revealed a main effect of phase (Wilks's $\Lambda=.66 ; F(4,28)=3.68 ; p=$ $\left..01 ; \eta^{2}=.35\right)$ which fitted a nonlinear, order 4 trend (Figure 7; $\left.F(1,31)=15.47 ; p<.0005 ; \eta^{2}=.33\right)$. Bonferroni post-hoc analysis revealed the following order: phase $_{1}=$ phase $_{2}=$ phase $_{3}>$ phase $_{4}<$ phase $_{5}$. A between-subject ANOVA did not yield any significant main effects or interactions between the variables of interest.

An ANOVA conducted on the dominance data revealed a main effect of phase (Wilks's $\Lambda=.66 ; F(4,30)=3.75 ; p<.01$; $\eta_{\mathrm{p}}^{2}=.33$ ) which fitted a nonlinear, cubic model (Figure 7; $\left.F(1,33)=14.06 ; p=.001 ; \eta_{\mathrm{p}}^{2}=.30\right)$. Bonferroni contrasts 
[0-10 scale]

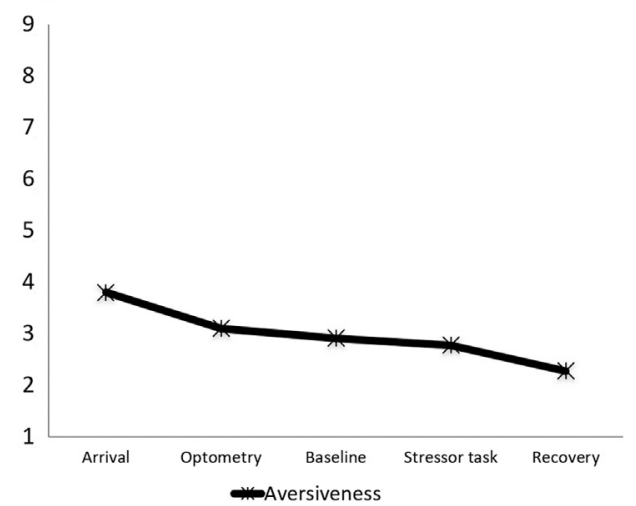

Figure 7. Means for the affective dimensions (arousal, valence, and dominance) assessed by the Self-Assesment-Manikin (SAM) and the scale of aversiveness to intraocular pressure (IOP) measurement throughout the phases of the study (values for aversiveness have been adjusted to a 1-9-points scale).

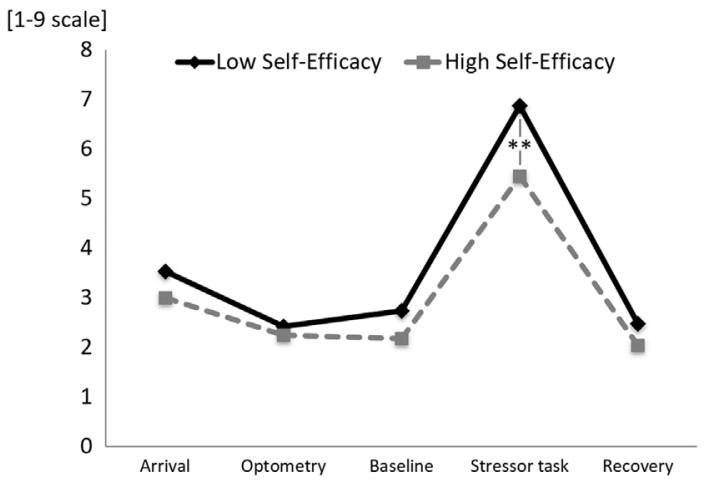

Figure 8. Estimated mean arousal as a function of dichotomized threat and self-efficacy (SE) subscales of PASA (Primary and Secondary Assessment) for each of the five phases of the study. Asterisks reflect the between-subject significant effects $(* * p<.01)$.

revealed the following order: phase $_{1}<$ phase $_{2}=$ phase $_{3}>$ phase $_{4}<$ phase $_{5}$. A between-subject ANOVA revealed a main effect of self-efficacy (Figure 9): subjects with higher self-efficacy showed higher dominance $(M=6.67$ vs. $M=$ 5.02; $\left.F(1,33)=11.75 ; p=.002 ; \eta_{\mathrm{p}}^{2}=.26\right)$.

An ANOVA conducted on the aversiveness of IOP measurement revealed a main effect of phase (Wilks's $\Lambda=.55$; $\left.F(4,28)=5.65 ; p<.002 ; \eta^{2}=.45\right)$ which only fitted a linear, decreasing trend (Figure 7; $F(1,31)=29.83 ; p<.0005 ; \eta^{2}=$ .44). Bonferroni contrasts revealed the following order: phase $_{1}>$ phase $_{2}=$ phase $_{3}>$ phase $_{4}=$ phase $_{5}$. A betweensubject ANOVA found main effects of both threat and self-efficacy (Figure 10): Participants with a higher level of perceived threat showed lower aversiveness $(M=1.70$ vs. $\left.M=3.29 ; F(1,33)=4.77 ; p=.03 ; \eta_{\mathrm{p}}^{2}=.13\right)$ and those with higher self-efficacy also showed lower aversiveness $\left(M=1.78\right.$ vs. $\left.M=3.21 ; F(1,32)=4.13 ; p=.05 ; \eta^{2}=.11\right)$.

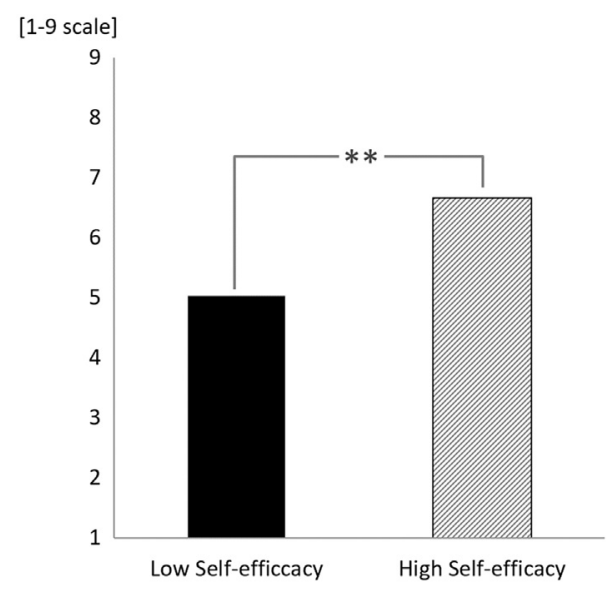

Figure 9. Estimated mean dominance as a function of dichotomized threat and self-efficacy (SE) subscales of PASA (Primary and Secondary Assessment) for each of the five phases of the study. Asterisks reflect the between-subject significant effects $\left({ }^{* *} p<.01\right)$.

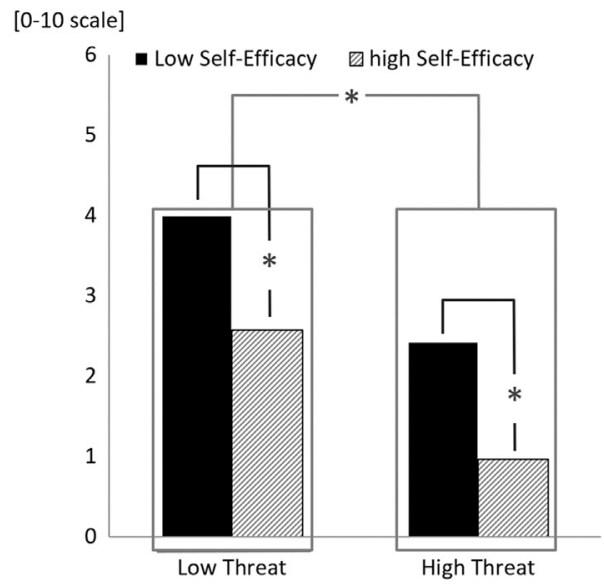

Figure 10. Estimated mean aversiveness of IOP measurement as a function of dichotomized threat and self-efficacy (SE) subscales of PASA (Primary and Secondary Assessment) for each of the five phases of the study. Asterisks reflect the between-subject significant effects $\left({ }^{*} p<.05\right)$.

\section{Common Versus Specific Regulatory Mechanisms for Psychophysiological Variables}

Although all the physiological variables shared a common topography (a progressive tendency to decline from Phase 1 (arrival) to Phase 3 (baseline), sharply disrupted by a peak during the stressor task (Phase 4), two distinct patterns appear to emerge, grouping SBP, DBP and HR. and IOP for $\mathrm{LE}$ and $\mathrm{RE}$ on the other hand. In order to test the significance of this apparent grouping, individual within-subject Pearson's correlations were computed (i.e., a correlation matrix for each participant $(n=38)$ was computed from 
Table 2. Correlation of IOP and cardiovascular parameters

\begin{tabular}{llllc}
\hline & DBP & Heart rate & IOP left eye & IOP right eye \\
\hline SBP & .81 & .62 & .33 & .21 \\
DBP & & .61 & .23 & .17 \\
Heart rate & & & .22 & -.04 \\
IOP left eye & & & & .27
\end{tabular}

Note. SBP = Systolic Blood Pressure; DBP = Diastolic Blood Pressure; $\mathrm{IOP}=$ Intraocular Pressure.

absolute values of 5 variables $\times 5$ phases). Table 2 shows the grand averages of these within-subject correlations.

The results showed that mean within-subject correlations range from $r=-.04$ (HR with IOP-RE) to $r=.81$ (SBP with DBP). A within-subject ANOVA conducted on these "metacorrelations" revealed significant differences in mean within-subject correlations (Wilks's $\Lambda=.33 ; F(9,28)=$ 13.78; $\left.p<.0005 ; \eta_{\mathrm{p}}^{2}=.28\right)$. Bonferroni contrasts grouped the correlations into the following four groups: $r_{(\mathrm{SBP}, \mathrm{DBP})}>$ $r_{(\mathrm{SBP}, \mathrm{HR})}=r_{(\mathrm{DBP}, \mathrm{HR})}>r_{(\mathrm{SBP}, \mathrm{IOP})}=r_{(\mathrm{DBP}, \mathrm{IOP})}=r_{(\mathrm{HR} ; \mathrm{IOP}) .}$. Further, two principal component analyses (PCA) were carried out in order to test whether a one-dimension or a twodimension model was the best fit for grouping the patterns in terms of physiological variables. Physiological raw data were reduced to mean samples in order to control for individual variability, and then normalized ( $Z$-scores) in order to homogenise the scales of measurement.

As it can be observed in Table 3, a one-dimension factorial solution explained $81.8 \%$ of the variance, and physiological variables had a factorial load in the range $.85^{-} .96$. A two-dimension factorial solution (with Varimax rotation) explained $99.6 \%$ of the variance, grouping the cardiovascular variables in Factor 1 with factorial loadings in the range $.93-.96$ and grouping the IOP measurements in Factor 2 with factorial loadings in the range .93-.95. In spite of this, IOP contributed to the cardiovascular reactivity factor with factorial loadings from .30 to .36 and reciprocally cardiovascular variables contributed to the IOP reactivity factor with factorial loadings from .29 to .37 .

As a complementary strategy for identifying the covariation of physiological variables, an array of 38 principal
Table 4. Number of subjects of the sample $(n=38)$ in which a pair of physiological variables loaded in the same factor $>.70$ in the individual factor analysis (PCA, two-dimensions extracted)

\begin{tabular}{lcccc}
\hline & DBP & HR & IOP-LE & IOP-RE \\
\hline SBP & 27 & 23 & 11 & 10 \\
DBP & & 22 & 12 & 9 \\
HR & & 13 & 6 \\
IOP-LE & & & & 18 \\
\hline
\end{tabular}

Note. $\mathrm{SBP}=$ Systolic Blood Pressure; $\mathrm{DBP}=$ Diastolic Blood Pressure; $\mathrm{HR}=$ Heart Rate; IOP-LE = Intraocular Pressure - Left Eye; IOP-RE = Intraocular Pressure - Right Eye; PCA = Principal Component Analyses .

Table 5. Adjustment to linear, quadratic, and cubic models of regression of aversiveness to IOP measurement (regressor) and IOP (dependent variable)

\begin{tabular}{|c|c|c|c|c|c|c|}
\hline & \multicolumn{2}{|c|}{$\underline{\text { Linear model }}$} & \multicolumn{2}{|c|}{$\begin{array}{c}\text { Quadratic } \\
\text { model }\end{array}$} & \multicolumn{2}{|c|}{ Cubic model } \\
\hline & $R^{2}$ & $p$ & $R^{2}$ & $p$ & $R^{2}$ & $p$ \\
\hline Arrival & .01 & .54 & .07 & .32 & .08 & .52 \\
\hline Optometry & .01 & .54 & .05 & .47 & .08 & .50 \\
\hline Baseline & .03 & .34 & .09 & .24 & .09 & .42 \\
\hline Stressor & .02 & .40 & .19 & .04 & .19 & .08 \\
\hline Recovery & .01 & .67 & .02 & .76 & .03 & .86 \\
\hline
\end{tabular}

component analyses was carried out (one per subject). Two factors were extracted, and factor loadings were calculated with VARIMAX rotation. Each pair of variables were declared as covariates if both had a factor loading above .70. Table 4 displays the number of subjects for which this criterion was reached for each pair of variables:

\section{Aversiveness of the Measurement Procedure and IOP}

In order to analyze the relationship between aversiveness of the procedure and variability in IOP for each phase of the study, a series of linear, quadratic, and cubic regressions were planned, where aversiveness was the regressor and IOP the dependent variable. The results (see Table 5) failed to show a relationship between these two variables in any of

Table 3. Comparison of two-factorial models for physiological reactivity along the study

\begin{tabular}{lccc}
\hline & One-dimension PCA model & \multicolumn{2}{c}{ Two-dimensions PCA model } \\
\cline { 2 - 3 } & Factor 1 Loadings & Factor 1 loadings & Factor 2 loadings \\
\hline SBP & .96 & .93 & .37 \\
DBP & .93 & .96 & .29 \\
Heart rate & .95 & .94 & .30 \\
IOP left eye & .83 & .36 & .95 \\
IOP right eye & .85 & $57.5 \%$ & .93 \\
Variance explained per factor & & & $42.1 \%$ \\
Variance explained per model & $81.6 \%$ & $99.6 \%$ \\
\hline
\end{tabular}

Note. SBP = Systolic Blood Pressure; DBP = Diastolic Blood Pressure; HR = Heart Rate; IOP = Intraocular Pressure; PCA = Principal Component Analyses. 
the phases, with the exception of Phase 4 , in which the quadratic model reached statistical significance.

\section{Discussion}

At first glance, the results reported here indicate that the participants were sensitive to the demands of the task throughout the study, since all the dependent variables measured showed a significant effect of phase. Of particular interest was the physiological and affective response to the social stressor task, characterized by an increase in SBP, DBP, HR, IOP, and arousal, and by a decrease in valence and dominance. The perceived aversiveness of the IOP measurement procedure was the only measured variable that did not appear to be reactive to the social stressor task and instead showed a sustained tendency to decrease throughout the course of the study, despite the demands of the various phases.

It is worth noting that we found a significant difference in IOP between the two eyes throughout the study. Undoubtedly, healthy individuals can show a lateralization in IOP (Dane, Gümüştekin, Yacizy, \& Baykal, 2003), a difference that appears to be related to sympathetic asymmetry (Reddy \& Mohan, 2010), and this strong IOP asymmetry can be a risk factor for glaucoma (Williams et al., 2013). In the general population there is an increase in RE IOP, an effect that is particularly marked in right-handed people. In contrast, in our study LE IOP was consistently enhanced throughout the phases. Moreover, in our sample the vast majority of the participants (83.3\%) were right-handed. Therefore, there is no anatomical or physiological basis for our results. One possible explanation could lie in our chosen methodology. In particular, this difference between LE and RE IOP could be explained in terms of a habituation process affecting the second eye to be measured (RE), which would further confirm that psychological processes have an impact on IOP.

Regarding the role of perceived control in physiological and affective functioning, the results obtained clearly support our hypothesis. Thus, an interaction between selfefficacy and threat could partially explain individual differences in cardiovascular response to the demands of the study. Subjects experiencing threat with a high sense of self-efficacy sustained elevated levels of SBP and DBP throughout all the phases compared with participants in the other three conditions. The former group also showed an enhanced HR reactivity on the stressor task, although this failed to reach statistical significance. For this variable, the interaction was limited to the stressor task, and indicated that the subjects with low self-efficacy and high threat were more reactive. This pattern of results is similar to that reported in previous studies (Gerin et al., 1995, 1996; Sanz \& Villamarín, 2001), in which high elevations in blood pressure (particularly DBP) and moderate increases in HR are indicative of active coping, while higher HR reactivity and moderate changes in blood pressure are indicative of anxiety and stress as a physiological state that prepares the individual for an avoidance response (Sanz, Villamarín, \& Álvarez, 2006). This is also congruent with the results obtained with regard to affect, since subjects with high self-efficacy (despite their perceived level of threat) showed lower arousal and higher dominance throughout all the phases of the study. Our results also indicate that perceived control affected IOP in a manner similar to that of SBP and DBP. Again, an interaction was found, since subjects with higher levels of self-efficacy and threat showed an increased IOP in comparison with those in the other three conditions, although this difference reached statistical significance in the two phases (optometry and stressor social test) in which an overt response was required by the subjects. Therefore, the results suggest that IOP is not only sensitive to the psychosocial demands of the context, but (as with the case of blood pressure) is also regulated by the levels of perceived control, which serves as a preparatory strategy for active coping.

Regarding the perceived aversiveness of the IOP measurement procedure, it has been argued that this depends on the degree of discomfort caused by the invasion of personal space, along with manipulation of the eye. Such discomfort could be an important source of stress that explains changes in IOP. This assertion, however, is not supported by our results, since there were negligible correlations between IOP and the perceived aversiveness of the IOP measurement (none of these were statistically significant) throughout the five phases of the study. Moreover, the aversiveness ratings were generally low in the total sample and declined throughout the course of the study. This hypothesis was initially derived from the results obtained in studies in which Goldmann tonometry was employed. This procedure is highly invasive and implies the use of anaesthesia and contact between the tonometer and the surface of the eye. In contrast, we employed a noncontact tonometer, which can be regarded as a less invasive or threating instrument.

Despite the seemingly similar topography of IOP and cardiovascular variables throughout the study, two main differences emerged between them: IOP showed a clear tendency to decline throughout the phases, with moderate reactivity to the social stressor task. Cardiovascular variables, however, did not show any general trend and remained stable over time but showed intense reactivity to the social stressor. The statistical analyses clearly classified the individual variability into two slightly related but different factors, the most important of which included 
SBP, DBP, and HR, and the second of which only included IOP for both eyes. Therefore, regarding the regulatory mechanisms underlying the reactivity of physiological parameters measured in this study, our findings, as expected, suggest a common mechanism for cardiovascular variables, sharing between $37 \%$ and $65 \%$ of the variability observed. In contrast, only a weak covariation was found among cardiovascular variables and IOP, since SBP, DBP, and HR only shared $5-10 \%$ of the variability with IOP. These results are consistent with the findings of previous research (Méndez-Ulrich et al., 2013) and do not support the theoretical assertion of a shared regulatory mechanism for IOP and the cardiovascular system. Undoubtedly, the lack of specificity of control exerted by the autonomic system, as postulated by Selye (1956), has been brought into question. There is a vast body of evidence suggesting high specialization of the neurons of the sympathetic and parasympathetic systems, which are involved in the specific regulation of each of the target organs (Furlan et al., 2016). This is congruent with evidence suggesting that the autonomic nervous system is organized (in the words of Norman, Berntson, \& Cacioppo, 2014) as a heterarchy in which two effector systems can exhibit a different pattern of autonomic regulation while a single effector system changes its autonomic space regulation over time (Berntson et al., 1994).

Taken together, the results obtained in this study support the notion that IOP reactivity is influenced by cognitive processes, and runs parallel to affective changes, which could be the basis for suggesting a hypothetical white coat effect on the ocular system. However, this possibility should be explored in glaucoma patients due to the fact that they have a hypothetically different physiology in comparison with healthy subjects and that, unlike healthy individuals, they are accustomed to experiencing fear as a result of the measurement procedure. However, this assertion should be treated with caution since we have found evidence that, while IOP and cardiovascular reactivity may be parallel, they are essentially independent processes, and thus the $\mathrm{OWCH}$, if it exists, would be an analogous but very different phenomenon to that of white coat hypertension. Therefore, the results obtained here suggesting a link between IOP and both cognitive and emotional processing can be seen as supporting a relationship between these processes and transient elevations in IOP, but do not necessarily imply that these processes play some role in the aetiology of glaucoma. Therefore, the usefulness of these results is that they suggest the convenience of taking this effect into account in further clinical research, since glaucoma could be over-diagnosed.

On the basis of the results obtained here, we conclude by responding to the questions set out in our original hypotheses:
Hypothesis 1 (H1). Did the psychosocial stressors present in the clinical setting cause significant IOP and cardiovascular reactivity? Our results strongly support this hypothesis: IOP declines over time and is moderately sensitive to psychosocial stressors, while SBP, DBP, and HR are stable over time and highly reactive to psychosocial stressors.

Hypothesis 2 (H2). Are individual differences in IOP reactivity to psychosocial stressors partially dependent on the interaction between self-efficacy and threat? Our results strongly support this hypothesis: The combination of high self-efficacy and high threat appeared to render the participant more susceptible to higher tonic or phasic changes in IOP, along with higher SBP and DBP levels. This condition was also characterized by moderate to high HR reactivity, higher dominance, lower arousal, and lower perceived aversiveness of the IOP measurement procedure. For all of the dependent variables, we found a main effect of selfefficacy, or an interaction between self-efficacy and threat.

Hypothesis 3 (H3). Did a high level of perceived aversiveness of the IOP measurement procedures partially predict individual differences in IOP? Our results failed to support this hypothesis: Aversiveness decreased over time, independently of IOP values. Thus, aversiveness did not appear to account for the individual variability in IOP when employing non-contact tonometry.

Hypothesis 4 (H4). Was there a strong correlation between IOP and cardiovascular reactivity when faced with a psychosocial stressor? Our results failed to confirm a common regulatory mechanism for all the physiological variables analysed. SBP and DBP appeared to be highly correlated over time, and HR shared a moderate to high covariation with SBP and DBP, but IOP changed over time independently of cardiovascular variables. A specific regulatory model would better fit the results obtained. As a whole: Did the results provide support for the phenomenon of ocular white coat hypertension? The evidence derived from this study is strongly compatible with an ocular white coat effect. In our opinion, this encourages further clinical research to specifically address this hypothetical phenomenon. However, our results in relation to this hypothesis should only be considered as a preliminary step toward addressing this issue, since the study was conducted with a healthy sample, and this phenomenon should be tested in clinical contexts with real glaucoma patients in order to evaluate its relevance for ophthalmologic clinical practice.

This study makes a contribution to an emerging field in Health Psychology that has been named "PsychoOphthalmology" (Méndez-Ulrich \& Sanz, 2016) in which three major areas of research have been initiated: the effects of stress on IOP, the emotional impact of ocular diseases, and adherence to treatment. In our opinion, the chief contribution of this study is that it provides an empirical basis for postulating the existence of ocular white-coat 
hypertension. Thus, our findings support the possibility that some of the determinants of white-coat hypertension could also underlie IOP reactivity. In the future, clinical trials should be conducted to characterize this hypothetical phenomenon. And, if effectively confirmed, it must be included in measurement protocols of IOP, as is now a matter of routine with respect to blood pressure (O'Brien et al., 2003).

As argued in the discussion, the lack of covariation between cardiovascular variables and IOP in the presence of psychosocial stressors could be explained in terms of a specific regulatory mechanism that operates for each of these, a notion that has received empirical support from anatomical and physiological research (Berntson et al., 1994). However, there is an alternative methodological reason that could underlie this lack of covariation. In addition, some studies postulated that the reactivity of IOP to stress, and even loss of vision, could be regulated by a mechanism called the "eye-brain-vascular triad" (Sabel, Flammer, \& Merabet, 2018; Sabel, Wang, Cárdenas-Morales, Faiq, \& Heim, 2018). This hypothesis represents an interesting alternative that should be explored in more depth in future studies on the physiology of IOP reactivity to stress. In the present study cardiovascular variables were simultaneously measured during a brief interval (20 s approximately) while IOP was measured four times during a later 2-minute period. This lack of synchronicity in the measurement of the psychophysiological variables is a limitation that should be addressed in next studies. In any case, the results obtained in this study encourage future research aimed at disentangling the relationship between stress and IOP, on the one hand, and to identify a possible white-coat effect that affects the ocular system, on the other.

\section{References}

Association for the Advancement of Medical Instrumentation (ANSI/AAMI). (2013). Non-invasive sphygmomanometers. Part 2: Clinical investigation of automated measurement type. Retrieved from http://my.aami.org/aamiresources/previewfiles/8106002_ 1306_preview.pdf

Bandura, A. (1977). Self-efficacy: Toward a unifying theory of behavioral change. Psychological Review, 84, 191-215. https:// doi.org/10.1037/0033-295X.84.2.191

Bandura, A. (1992). Self-efficacy mechanisms in psychobiologic functioning. In R. Schwarzer (Ed.), Self-efficacy: Thought control of action (pp. 355-394). Washington, DC: Hemisphere.

Bandura, A., Reese, L., \& Adams, N. E. (1982). Microanalysis of action and fear arousal as a function of differential levels of perceived self-efficacy. Journal of Personality and Social Psychology, 43, 5-21. https://doi.org/10.1037/0022-3514.43.1.5

Berntson, G. G., Cacioppo, J.T., Binkley, P. F., Uchino, B. N., Quigley, K. S., \& Fieldstone, A. (1994). Autonomic cardiac control. III. Psychological stress and cardiac response in autonomic space as revealed by pharmacological blockades. Psychophysiology, 31, 599-608. https://doi.org/10.1111/j.1469-8986.1994. tb02352.x
Blázquez, F., Sebastián, M. A., \& Antón, A. (2008). Detection of glaucoma using SisGlaTel: Acceptability and satisfaction among participants, and problems detected. Archivos de La Sociedad Española de Oftalmología, 83, 533-538. https://doi. org/10.4321/S0365-66912008000900005

Bradford, C. A. (2004). Basic ophthalmology (8th ed.). San Francisco, CA: American Academy of Ophthalmology.

Bradley, M. M., \& Lang, P. J. (1994). Measuring emotion: The selfassessment manikin and the semantic differential. Journal of Behavior Therapy and Experimental Psychiatry, 25, 49-59. https://doi.org/10.1016/0005-7916(94)90063-9

Brewer, M. (2000). Research design and issues of validity. In H. Reis \& C. Judd (Eds.), Handbook of research methods in social and personality psychology (pp. 266-268). Cambridge, UK: Cambridge University Press.

Brody, S., Erb, C., Veit, R., \& Rau, H. (1999). Intraocular pressure changes: The influence of psychological stress and the Valsalva manoeuvre. Biological Psychology, 51, 43-57. https://doi.org/ 10.1016/S0301-0511(99)00012-5

Chen, W., Chen, Z., Xiang, Y., Deng, C., Zhang, H., \& Wang, J. (2019). Simultaneous influence of sympathetic autonomic stress on Schlemm's canal, intraocular pressure and ocular circulation. Scientific Reports, 9, 20060. https://doi.org/ 10.1038/s41598-019-56562-0

Chiquet, C., \& Denis, P. (2004). The neuroanatomical and physiological bases of variations in intraocular pressure. Journal Français d'Ophtalmologie, 27, 2S11-2S18. https://doi. org/JFO-09-2004-27-HS2-0181-5512-101019-ART03

Dane, S., Gümüştekin, K., Yacizy, A.T., \& Baykal, O. (2003). Correlation between hand preference and intraocular pressure from right- and left-eyes in right- and left-handers. Vision Research, 43, 405-408. https://doi.org/10.1016/S0042-6989(02) 00568-0

Enström, I., Pennert, K., \& Lindholm, L. H. (2000). Difference in blood pressure, but not in heart rate, between measurements performed at a health centre and at a hospital by one and the same physician. Journal of Human Hypertension, 14, 355-358. https://doi.org/10.1038/sj.jhh.1001016

Erb, C., Brody, S., \& Rau, H. (1998). Einfluß von mentalem und physischem Streß auf den intraokulären Druck - eine Pilotstudie [Effect of mental and physical stress on intraocular pressure - a pilot study]. Klinische Monatsblätter für Augenheilkunde, 212, 270-274. https://doi.org/10.1055/s-20081034878

Feltz, D. L., \& Mugno, D. A. (1983). A replication of the path analysis of the causal elements in Bandura's theory of selfefficacy and the influence of autonomic perception. Journal of Sport Psychology, 5, 263-277. https://doi.org/10.1123/jsp.5. 3.263

Fogagnolo, P., \& Rossetti, L. (2011). Medical treatment of glaucoma: Present and future. Experimental Opinion on Investigational Drugs, 20, 947-959. https://doi.org/10.1517/ 13543784.2011.579901

Furlan, A., La Manno, G., Lübke, M., Häring, M., Abdo, H., Hochgerner, H., ... Enforns, P. (2016). Visceral motor neuron diversity delineates a cellular basis for nipple- and piloerection muscle control. Nature Neuroscience, 19, 13311340. https://doi.org/10.1038/nn.4376

Gaab, J., Rohlederb, N., Natera, U. M., \& Ehlerta, U. (2005). Psychological determinants of the cortisol stress response: the role of anticipatory cognitive appraisal. Psychoneuroendocrinology, 30, 599-610. https://doi.org/10.1016/j.psyneuen.2005.02.001

Gerin, W., Litt, M. D., Deich, J., \& Pickering, T. G. (1995). Selfefficacy as moderator of perceived control effects on cardiovascular reactivity: Is enhanced control always beneficial? Psychosomatic Medicine, 57, 390-397. 
Gerin, W., Litt, M. D., Deich, J., \& Pickering, T. G. (1996). Selfefficacy as a component of active coping: Effects on cardiovascular reactivity. Journal of Psychosomatic Research, 40, 485-493. https://doi.org/10.1016/0022-3999(95)00642-7

Gherezghiher, T., Hey, J. A., \& Koss, M. C. (1990). Parasympathetic nervous control of intraocular pressure. Experimental Eye Research, 50, 457-462. https://doi.org/10.1016/0014-4835(90) 90032-P

Guyton, A., \& Hall, J. E. (2006). Textbook of medical physiology (11th ed.). Philadelphia, PA: Elsevier Saunders.

Kaluza, G., \& Maurer, H. (1997). Stress and intraocular pressure in open angle glaucoma. Psychology \& Health, 12, 667-675. https://doi.org/10.1080/08870449708407413

Kaluza, G., Strempel, I., \& Maurer, H. (1996). Stress reactivity of intraocular pressure after relaxation training in open-angle glaucoma patients. Journal of Behavioural Medicine, 19, 587-598. https://doi.org/10.1007/BF01904906

Kanski, J. J., \& Bowling, B. (2011). Clinical ophthalmology (7th ed.). Edinburgh, UK: Elsevier Saunders.

Kirschbaum, C., Pirke, K. M., \& Hellhammer, D. (1993). The "Trier Social Stress Test" - A tool for investigating psychobiological stress responses in a laboratory setting. Neuropsychobiology, 28, 76-81. https://doi.org/10.1159/000119004

Lawson-Kopp, W., DeJong, A., Yudcovitch, L., Williams, S., Kohl, P., \& Yolton, R. L. (2002). Clinical evaluation of the Keeler Pulsair 3000 non-contact tonometer. Optometry, 73, 81-90. https:// doi.org/10.1016/j.optom.2013.06.002

Lazarus, R. S., \& Folkman, S. (1984). Stress, appraisal, and coping. New York, NY: Springer.

MacDonald, M. B., Laing, G. P., Wilson, M. P., \& Wilson, T. W. (1999). Prevalence and predictors of white-coat response in patients with treated hypertension. Canadian Medical Association Journal, 161, 265-269. Retrieved from https://www.ncbi. $\mathrm{nlm}$.nih.gov/pmc/articles/PMC1230502/

Méndez-Ulrich, J. L., Casas, N., \& Sanz, A. (2013). Hipertensión ocular de bata blanca: Un estudio Piloto [Ocular white coat hypertension: A pilot study]. Ansiedad y Estrés, 19, 41-51.

Méndez-Ulrich, J. L., \& Sanz, A. (2016). Psycho-ophthalmology: Health psychology in the assessment and treatment of glaucoma. Psychology \& Health, 32, 330-342. https://doi.org/ 10.1080/08870446.2016.1268690

Norman, G. J., Berntson, G. G., \& Cacioppo, J. T. (2014). Emotion, somatovisceral afference, and autonomic regulation. Emotion Review, 6, 113-123. https://doi.org/10.1177/1754073913512006

O’Brien, E., Asmar, R., Beilin, L., Imai, Y., Mallion, J. M., Mancia, G., ... European Society of Hypertension Working Group on Blood Pressure Monitoring. (2003). European Society of Hypertension recommendations for conventional, ambulatory and home blood pressure measurement. Journal of Hypertension, 21, 821-848. https://doi.org/10.1097/00004872-200305000-00001

Ogedegbe, G., Pickering, T. G., Clemow, L., Chaplin, W., Spruill, T. M., Albanese, G. M., ... Gerin, W. (2008). The misdiagnosis of hypertension: The role of patient anxiety. Archives of Internal Medicine, 168, 2459-2465. https://doi.org/10.1001/archinte.168. 22.2459

Ogbuehi, K. C., \& Almubrad, T. M. (2008). Accuracy and reliability of the Keeler Pulsair EasyEye non-contact tonometer. Optometry and Vision Science, 85, 61-66. https://doi.org/10.1097/ OPX.0b013e31815ed742

Parker, V. A., Herrtage, J., \& Sarkies, N. J. C. (2001). Clinical comparison of the Keeler Pulsair 3000 with Goldman aplanation tonometry. British Journal of Ophthalmology, 85, 13031304. https://doi.org/10.1136/bjo.85.11.1303

Paton, J. F. R., Boscan, P., Pickering, A. E., \& Nalivaiko, E. (2005). The yin and yang of cardiac autonomic control: Vago-sympathetic interactions revisited. Brain Research Reviews, 49, 555-565. https://doi.org/10.1016/j.brainresrev.2005.02.005

Paul, M. (2006). Non-contact tonometers. Kerala Journal of Ophthalmology, 18, 221-223.

Pickering, T. G., Gerin, W., \& Schwartz, A. R. (2002). What is the white-coat effect and how should it be measured? Blood Pressure Monitoring, 7, 293-300. https://doi.org/10.1097/01. mbp.0000053044.16575.8b

Rao, A. (2012). Normotensive pseudoesfoliation glaucoma: A new phenotype? Seminars in Ophthalmology, 27, 48-51. https://doi. org/10.3109/08820538.2011.631513

Reddy, S. C., \& Mohan, S. M. (2010). Intraocular pressure as indicator of sympathetic asymmetry in the eyes. International Journal of Ophthalmology, 3, 326-327.

Rotter, J. B. (1975). Some problems and misconceptions related to the construct of internal versus external control of reinforcement. Journal of Consulting and Clinical Psychology, 43, 56-67. https://doi.org/10.1037/h0076301

Sabel, B. A., Flammer, J., \& Merabet, L. B. (2018). Residual vision activation and the brain-eye-vascular triad: Dysregulation, plasticity and restoration in low vision and blindness - a review. Restorative Neurology and Neuroscience, 36, 767-791.

Sabel, B. A., Wang, J., Cárdenas-Morales, L., Faiq, M., \& Heim, C. (2018). Mental stress as consequence and cause of vision loss: The dawn of psychosomatic ophthalmology for preventive and personalized medicine. EPMA Journal, 9, 133-160.

Sauerborn, G., Schmitz, M., Franzen, U., \& Florin, I. (1992). Stress and intraocular pressure in myopes. Psychology and Health, 6 , 61-68. https://doi.org/10.1080/08870449208402022

Sanz, A., \& Villamarín, F. (1997). Interactive effect of self-efficacy and incentive value on peripheral physiological reactivity in the performance of a cognitive task. Psicothema, 8, 491-505.

Sanz, A., \& Villamarín, F. (2001). The role of perceived control in psychological reactivity: Self-efficacy and incentive value as regulators of cardiovascular adjustment. Biological Psychology, 56, 219-246. https://doi.org/10.1016/S0301-0511(01)00095-3

Sanz, A., Villamarín, F., \& Álvarez, M. (2006). Effects of specific and non-specific perceived control on blood pressure response in a stressful mental task. Biological Psychology, 71, 20-28. https://doi.org/10.1016/j.biopsycho.2005.01.010

Sanz, A., Villamarín, F., Álvarez, M., \& Limonero, J. T. (2006) Microanalysis of the relationship between self-efficacy and cardiovascular reactivity. A test for the moderating role of the incentive value and the mediating role of anxiety. International Journal of Psychophysiology, 62, 66-76. https://doi.org/ 10.1016/j.ijpsycho.2006.01.013

Sanz, A., Villamarín, F., Álvarez, M., \& Torrubia, R. (2007) Sensitivity to punishment as a moderator of the relationship between self-efficacy and cardiovascular reactivity. Personality and Individual Differences, 43, 143-154. https://doi.org/ 10.1016/j.paid.2006.11.016

Stemmler, G., \& Wacker, J. (2010). Personality, emotion, and individual differences in physiological responses. Biological Psychology, 84, 541-551. https://doi.org/10.1016/j.biopsycho. 2009.09.012

Selye, H. (1956). The stress of life. New York, NY: McGraw-Hill.

Skinner, E. A. (1996). A guide to constructs of control. Journal of Personality and Social Psychology, 71, 549-570. https://doi. org/10.1037/0022-3514.71.3.549

Van der Valk, R., Webers, C. A. B., Shouten, J. S. A. G., Zeegers, M., Hendrikse, F., \& Prins,, M. H. (2005). Intraocular pressure-lowering effects of all commonly used glaucoma drugs: A meta-analysis of randomized clinical trials. Ophthalmology, 112, 1177-1185. https://doi.org/10.1016./j.ophtha. 2005.01.042 
Williams, A. L., Gatla, S., Leiby, B. E., Fahmy, I., Biswas, A., de Barros, D. M., ... Spaeth, G. L. (2013). The value of intraocular pressure asymmetry in diagnosing glaucoma. Journal of Glaucoma, 22, 215-218. https://doi.org/10.1097/ IJG.0b013e318237bfb8

Wilson, M. R., Coleman, A. L., Yu, F., Sasaki, I. F., Bing, E. G., \& Kim, M. H. (2002). Depression in patients with glaucoma as measured by self-report surveys. Ophthalmology, 109, 10181022. https://doi.org/10.1016/S0161-6420(02)00993-4

Wright, R., \& Dill, J. C. (1993). Blood pressure responses and incentive appraisals as a function of perceived ability and objective task demand. Psychophysiology, 30, 152-160. https:// doi.org/10.1111/j.1469-8986.1993.tb01728.x

Wright, R. A., \& Dismukes, A. (1995). Cardiovascular effects of experimentally induces efficacy (ability) appraisals at low and high levels of avoidant task demand. Psychophysiology, 32, 172-176. https://doi.org/10.1111/j.1469-8986.1995.tb03309.x

Wright, R., Shaw, L., \& Jones, C. (1990). Task demand on cardiovascular response: Further evidence of mediating role of success importance. Journal of Personality and Social Psychology, 59, 1250-1260.

Yamamoto, K., Sakamoto, Y., Irie, M., Ohmori, S., Yoshinari, M., \& Kaçaniku, G. (2008). The relationship between IMPS-measured stress score and intraocular pressure among public school workers. Journal of Physiological Anthropology, 27, 43-50. https://doi.org/10.2114/jpa2.27.43

\section{History}

Received November 13, 2019

Revision received April 6, 2020

Accepted April 8, 2020

Published online May 27, 2020

\section{Acknowledgments}

We thank Josep Maria Vilaseca, Cristina Sotoca, Judith Mirallas, and the staff of the Òptica Universitària (UAB) for their appreciated contribution to this study.

\section{Conflict of Interest}

The authors declare that they have no financial interest or other benefit.

\section{Publication Ethics}

All procedures performed in this study involving human participants were in accordance with the ethical standards of the institutional and/or national research committee and with the 1964 Helsinki declaration and its later amendments or comparable ethical standards.

Informed consent was obtained from all individual participants included in the study.

\section{Funding}

This research was funded by Ministerio de Educación, Cultura y Deporte (Spanish Government; Grant SEJ2006-12418/PSIC).

\section{Jorge Luis Méndez-Ulrich}

Department of Methods of Research and Diagnosis in Education Faculty of Education

University of Barcelona

Barcelona, Catalonia

Spain

jordi.mendez@ub.edu 